\title{
Effects of xanthine amine congener on hypoxic coronary resistance and venous and epicardial adenosine concentrations
}

\author{
Darrell R Sawmiller, Joel Linden, and Robert M Berne
}

\begin{abstract}
Objective: The aim was to define the contributions of interstitial and vascular adenosine in regulating coronary vascular resistance during hypoxia. To help in the assessment of adenosine in the vasodilator response, a potent adenosine receptor antagonist, xanthine amine congener (XAC), was used to block adenosine receptors. Methods: Seven isolated guinea pig hearts were perfused at constant flow with Krebs buffer. Coronary vascular resistance was determined during normoxia $\left(95 \% \mathrm{O}_{2}\right)$ and mild hypoxia $\left(60 \% \mathrm{O}_{2}\right)$ in the absence or presence of 200 or $400 \mathrm{nM}$ XAC. Interstitial fluid was sampled by the epicardial disc technique and the interstitial concentration of XAC (ISF[XAC]) was determined directly by a radioreceptor assay or as tritiated XAC. Venous and epicardial concentrations of adenosine were determined by high performance liquid chromatography. In six additional experiments, the vasodilator effect of $1 \mu \mathrm{M}$ intracoronary adenosine was measured in the absence or presence of 100 or $200 \mathrm{nM}$ XAC. Results: Mild hypoxia decreased coronary resistance by 37 (SEM 4)\% in the absence of XAC and $26(5) \%$ or $17(4) \%$ in the presence of 200 or $400 \mathrm{nM} \mathrm{XAC}$, respectively. ISF[XAC] rapidly equilibrated with [XAC] in the arterial perfusate or venous effluent. XAC $400 \mathrm{nM}$ markedly increased $(\mathrm{p}<0.05)$ the hypoxic levels of venous and epicardial fluid adenosine from $49(19)$ and $251(42) \mathrm{nM}$ to $75(11)$ and $495(48) \mathrm{nM}$, respectively. XAC 100-200 nM almost completely prevented the vasodilatation induced by 1 $\mu \mathrm{M}$ intracoronary adenosine. Conclusions: Adenosine mediates at least $54 \%$ of hypoxic vasodilatation. XAC rapidly equilibrates within the myocardial interstitial space and, as a result of blocking adenosine receptors, increases interstitial and venous adenosine concentrations. Increases in interstitial adenosine may partially overcome the adenosine receptor blockade by $\mathrm{XAC}$, thereby reducing the effectiveness of XAC in attenuating the hypoxic vasodilatation. XAC attenuates intracoronary adenosine induced vasodilatation (mediated by endothelial adenosine receptors) much more effectively than it attenuates hypoxic vasodilatation, underscoring the minimal role played by the endothelial receptors in hypoxic vasodilatation.

Cardiovascular Research 1994;28:604-609
\end{abstract}

$\mathrm{I}$ $t$ is well recognised that hypoxia induces coronary vasodilatation and that adenosine plays a role in this vasodilator response. ${ }^{1-3}$ Adenosine is released from the myocytes of hypoxic hearts and reaches vasoactive concentrations in the interstitial fluid and coronary venous effluent. ${ }^{1-6}$ In addition, hypoxic coronary vasodilatation has been shown to be attenuated by adenosine deaminase ${ }^{5-9}$ and the potent adenosine receptor antagonists 8-phenyltheophylline ${ }^{10}$ and BW-A1433. ${ }^{6}$ In each of these studies, the attenuation was incomplete, suggesting that hypoxic vasodilatation may not be solely mediated by adenosine. It is also possible that vascular adenosine deaminase or adenosine receptor antagonists do not penetrate sufficiently into the interstitial fluid to completely deaminate interstitial adenosine or block interstitial adenosine receptors. " 12 Furthermore, myocardial adenosine release may increase during adenosine receptor blockade and partially overcome the competitive blockade..$^{13}$ Indeed, adenosine appears to act as a mediator in the feedback system which couples myocardial oxygen requirements to coronary flow (oxygen supply). ${ }^{1-3}$ During adenosine receptor blockade, the feedback loop is opened and adenosine production may increase further to maintain coronary flow. If any of these possibilities occur, then adenosine might mediate a greater proportion of the total hypoxic vasodilatation than that shown in the studies using adenosine deaminase or receptor antagonists.
When using a competitive adenosine receptor antagonist to evaluate the role of adenosine in hypoxic coronary vasodilatation, it is useful to know the interstitial concentrations of both adenosine and the antagonist during normoxia and hypoxia. In previous studies, ${ }^{6}{ }^{10}$ the interstitial concentration of neither adenosine nor the antagonist was determined. The present study was undertaken to determine more clearly the extent to which adenosine is involved in hypoxic coronary vasodilatation in the isolated guinea pig heart. To this end, we studied the effect of intracoronary infusion of one of the most potent adenosine receptor antagonists, xanthine amine congener (XAC), ${ }^{15}$ on hypoxic coronary vasodilatation, and simultaneously measured the vascular and interstitial concentrations of adenosine and $X A C$. In addition, we compared the relative effectivenesses of $\mathrm{XAC}$ in attenuating hypoxic and intracoronary adenosine induced vasodilatations. The results enabled us to estimate the relative contributions played by adenosine receptors on coronary vascular smooth muscle ${ }^{1-3}$ and vascular endothelium, ${ }^{16-18}$ respectively, in hypoxic vasodilatation.

\section{Methods}

Perfusion protocol

Mature male Hartley guinea pigs (300-400 g body weight) were anaesthetised with $100 \mathrm{mg} \cdot \mathrm{kg}^{-1}$ ketamine and $20 \mathrm{mg} \cdot \mathrm{kg}^{-1}$ xylazine intramuscularly. A tracheostomy was performed and the animals were artificially ventilated. After thoracotomy, the caval veins were ligated

Department of Molecular Physiology and Biological Physics, Box 1116 MR 4 Annex, University of Virginia Health Science Center, Charlottesville, VA 22908, USA: D R Sawmiller, J Linden, R M Berne. Correspondence to Dr Sawmiller. 
and the hearts were rapidly excised and immersed in ice cold perfusion solution. The aorta was cannulated and the coronary arteries were retrogradely perfused with Krebs-Henseleit buffer containing (in mmol-litre ${ }^{-1}$ ): $\mathrm{NaCl} 119, \mathrm{KCl} 4.7, \mathrm{CaCl}_{2} 2.5, \mathrm{MgSO}_{4} 1.2, \mathrm{NaHCO}_{3} 25$, $\mathrm{KH}_{2} \mathrm{PO}_{4} 1.2$, glucose 5.5 , and pyruvate 2 . The perfusion solution was equilibrated with $95 \% \mathrm{O}_{2} / 5 \% \mathrm{CO}_{2}$, maintained at a temperature of $37^{\circ} \mathrm{C}$ and $\mathrm{pH}$ of 7.4. The hearts were paced at $4 \mathrm{~Hz}$ by ventricular stimulation and perfused at a constant flow rate of 9.6 (SEM 0.2) $\mathrm{ml} \cdot \mathrm{min}^{-1} \cdot \mathrm{g}^{-1}$ throughout the entire experiment, which yielded an initial perfusion pressure of $64(1) \mathrm{mm} \mathrm{Hg}$. A drain was introduced into the left ventricle via the mitral valve and placed in the cardiac apex to prevent accumulation of Thebesian drainage. Aortic pressure was monitored via a side port in the aortic cannula $5 \mathrm{~mm}$ above the level of the aortic valve. The pulmonary artery was cannulated for the collection of the coronary venous effluent for quantification of adenosine by high performance liquid chromatography (HPLC) and XAC by a radioreceptor assay, as described below. Arterial samples were collected from a side port in the aortic cannula $2 \mathrm{~cm}$ above the aortic valve. Coronary vascular resistance was determined continuously by dividing the perfusion pressure (in $\mathrm{mm} \mathrm{Hg}$ ) by the coronary flow rate $\left(\mathrm{ml} \cdot \mathrm{min}^{-1} \cdot \mathrm{g}^{-1}\right)$ and expressed in peripheral resistance units $\left(\mathrm{pru} \cdot \mathrm{g}^{-1}\right)$. All surgical procedures conformed with the guidelines of the University of Virginia animal research committee and were in accordance with National Institute of Health policies and the Guide for the care and use of laboratory animals (NIH Publication No 85-23, revised 1985).

\section{Experimental protocol}

Series 1. Effect of XAC on hypoxic vasodilatation $(n=7)-$ After equilibrating the hearts for $30 \mathrm{~min}$ with buffer gassed with $95 \% \mathrm{O}_{2} / 5 \%$ $\mathrm{CO}_{2}$, hypoxia was initiated by perfusing the hearts with buffer gassed with $60 \% \mathrm{O}_{2} / 35 \% \mathrm{~N}_{2} / 5 \% \mathrm{CO}_{2}$. Epicardial transudate, arterial perfusate and venous effluent samples for determination of adenosine and XAC concentrations were obtained before and 1-7 $\mathrm{min}$ after the induction of hypoxia. Coronary resistance was measured before and $7 \mathrm{~min}$ after the induction of hypoxia (after the time when resistance reached a steady state). After the samples were collected, the hearts were re-equilibrated for $30 \mathrm{~min}$ by perfusion with the normoxic buffer and then XAC (Research Biochemicals) was infused into a side port of the aortic cannula. The rate of infusion was adjusted to equal $1 / 100$ th of the coronary flow rate and to yield a final concentration of $200 \mathrm{nM}$ in the perfusion buffer. After $5 \mathrm{~min}$ of XAC infusion, hypoxia was initiated while maintaining the XAC infusion, and arterial, venous, and epicardial samples were obtained. The hearts were then re-equilibrated with the normoxic buffer. XAC was infused to yield a concentration of $400 \mathrm{nM}$, and hypoxia was initiated once again. The XAC solution used for infusion was prepared from a stock solution containing $1 \mathrm{mM} \mathrm{XAC}$ and $0.1 \mathrm{~N} \mathrm{NaOH}$. This stock was diluted in perfusion buffer and filtered $(0.45 \mu \mathrm{m})$ before infusion. In three experiments, the effect of vehicle alone $(20$ or $40 \mu \mathrm{N} \mathrm{NaOH})$ on hypoxic vasodilatation was determined.

Series 2. Effect of decreases in coronary perfusion pressure on venous adenosine concentration $(n=4)$ - Since hypoxia simultaneously decreases coronary perfusion pressure and increases venous adenosine concentration under the constant flow condition, a decrease in perfusion pressure alone could cause an increase in adenosine concentration. We determined if this is the case by assessing the effect of decreases in perfusion pressure alone induced by the coronary vasodilator pinacidil on venous adenosine concentration. Hearts were perfused at a constant flow rate of $9.1(0.3) \mathrm{ml} \cdot \mathrm{min}^{-1} \cdot \mathrm{g}^{-1}$ and after equilibration they were perfused in a cumulative fashion with pinacidil at 0.1-3 $\mu \mathrm{M}$ concentrations. Venous effluent samples were collected after $7 \mathrm{~min}$ perfusion at each concentration.

Series 3. Effect of XAC on adenosine induced vasodilatation $(n=6)$ - After equilibration, adenosine was infused at a concentration $(1 \mu M)$ that has been shown to produce near maximum vasodilatation. ${ }^{219}$ The hearts were then allowed to return to baseline resistance, perfused with 100 or $200 \mathrm{nM} \mathrm{XAC}$, and adenosine infusion was repeated after $5 \mathrm{~min}$ of the XAC perfusion.

Epicardial fluid sampling

Epicardial fluid was sampled with porous nylon discs as described previously. ${ }^{4}{ }^{20}$ Epicardial discs $6 \mathrm{~mm}$ in diameter (MicroSep Magna Nylon 66 Membrane Filters, Micron Separation Inc) with a pore size of $0.45 \mu \mathrm{m}$ were preweighed dry and then soaked in Krebs-Henseleit perfusate before application to the heart for a $1 \mathrm{~min}$ contact period. The epicardial sample collected before hypoxia consisted of four discs placed on the left ventricle in two consecutive pairs. This sample was used for determination of interstitial adenosine concentration. ${ }^{20}{ }^{21}$ The epicardial sample collected during hypoxia consisted of eight discs, in four consecutive pairs. Four discs were used for determination of interstitial adenosine concentration and four for determination of XAC concentration. After removal, the discs were reweighed to determine the volume of absorbed interstitial fluid, sealed inside sample tubes and stored at $-80^{\circ} \mathrm{C}$ until they were analysed for adenosine or XAC.
Quantification of adenosine by HPLC

Adenosine was analysed as described previously. ${ }_{4}^{4} 1321$ Four discs acquired at each time point were collectively thawed and placed in 40 $\mu l$ of distilled water to elute the sample. The samples were filtered through $0.22 \mu \mathrm{m}$ filters with the aid of centrifugation and placed in HPLC tubes. Of this sample, $175 \mu \mathrm{l}$ were injected onto a C-18 reverse phase column (Supelco, $5 \mu$ ) and eluted with a buffer gradient $(100 \mathrm{mM}$ $\mathrm{KH}_{2} \mathrm{PO}_{4}, 1 \%$ methanol, pH 5.53 at time zero, to $100 \mathrm{mM} \mathrm{KH}_{2} \mathrm{PO}_{4}$, $25 \%$ methanol, $\mathrm{pH} 5.58$ at $45 \mathrm{~min}$ ) at a flow of $1.3 \mathrm{ml} \cdot \mathrm{min}^{-1}$. Ultraviolet absorbance was continuously monitored at $254 \mathrm{~nm}$. Adenosine peaks were quantified by comparison of peak areas with those of standards. To calculate the epicardial purine concentration, the sample concentrations were multiplied by the sample dilution factor: $(400 \mu 1) / \mathrm{sample}$ volume $(\mu \mathrm{l})$. Venous effluent samples $(175 \mu \mathrm{l})$ were injected directly on the HPLC column for analysis.

Quantification of $X A C$ by radioreceptor assay

The four discs acquired during each hypoxic period for XAC analysis were collectively thawed and placed in $500 \mu \mathrm{l}$ of methanol to elute the $\mathrm{XAC}$. The discs from each sample were then placed in $500 \mu \mathrm{l}$ additional methanol, and the total sample was filtered, evaporated to dryness, and reconstituted in $175 \mu \mathrm{l} \mathrm{Krebs}$ buffer for XAC analysis. The arterial perfusate and venous effluent samples were analysed directly or diluted 1 to 10 with Krebs buffer.

The method used for the quantification of XAC was modified from a standard radioligand binding assay for $A_{1}$ adenosine receptors, which has been described previously.22 Aliquots $(25 \mu 1)$ of a bovine brain membrane suspension (0.05-0.1 mg protein) in HE buffer $[10 \mathrm{mM}$ $\mathrm{N}$-2-hydroxyethylpiperazine-N'-2-ethanesulphonic acid (HEPES), 1.0 $\mathrm{mM}$ ethylenediaminetetra-acetic acid (EDTA), $0.1 \mathrm{mM}$ benzamidine, $\left.0.02 \% \mathrm{NaN}_{3}, \mathrm{pH} 7.4\right]^{22}$ containing adenosine deaminase $\left(10 \mathrm{U} \cdot \mathrm{ml}^{-1}\right.$; Boehringer Mannheim) was mixed with $50 \mu \mathrm{l}$ of sample or standard (0.5-10 000 nM XAC in Krebs buffer). In some cases, XAC standards were also added to discs, processed as described above and assayed. Carrier-free ${ }^{125} \mathrm{I}-\mathrm{N}^{6}$-aminobenzyladenosine ( ${ }^{125} \mathrm{I}-\mathrm{ABA} ; 25 \mathrm{fmol}$ in $25 \mu \mathrm{I}$, $50 \mathrm{nCi})^{22}$ in $\mathrm{HE}$ buffer containing $0.01 \%$ 3-[(3-cholamidopropyl)dimethylammonio]-1-propanesulphonate (CHAPS) and $50 \mathrm{mM} \mathrm{MgCl}$ were then added. After a $2 \mathrm{~h}$ incubation, membranes were filtered over Whatman GF/C glass fibre filters presoaked with $0.3 \%$ polyethylenimine and then washed three times with ice cold buffer containing $10 \mathrm{mM}$ tris (hydroxy-methyl) aminomethane hydrochloride (Tris-HCl) and $1 \mathrm{mM} \mathrm{MgCl}$, $\mathrm{pH} 7.4$. Radioactivity trapped on the filters representing bound ${ }^{125}$ I-ABA was counted in a gamma counter. The XAC concentrations in the samples were determined based on their competition for ${ }^{125} \mathrm{I}-\mathrm{ABA}$ binding compared to that of the standards. There is little interference with this assay from endogenous materials in the epicardial fluid or venous effluent. Endogenous adenosine is eliminated by the addition of adenosine deaminase in the assay and inosine does not appreciably bind to the $A_{1}$ receptors in bovine brain membranes. In addition, samples collected in the absence of XAC perfusion did not produce detectable displacement of radioligand from the receptors.

In order to further determine if vascular XAC equilibrates with the interstitial fluid, two hearts were perfused with tritiated XAC and the concentrations of tritiated XAC in arterial perfusate, venous effluent, and epicardial disc samples were determined. The tritiated XAC (specific activity $\sim 100 \mathrm{Ci} \cdot \mathrm{mmol}$ ) was a gift from Richard Green (University of Illinois, Chicago, USA) and purified by thin layer chromatography as described previously. ${ }^{23}$ About $0.9 \mu \mathrm{Ci}$ of the purified tritiated XAC was mixed with $3 \mathrm{ml}$ of $20 \mu \mathrm{M}$ XAC and infused intra-arterially at a rate equal to $1 / 100$ th of the coronary flow rate. This vielded a final concentration of $200 \mathrm{nM}$ and $3 \mathrm{nCi} \cdot \mathrm{ml}^{-1}$ of tritiated XAC. Aliquots $(100 \mu 1)$ of the arterial perfusate or venous effluent samples were placed in $5 \mathrm{ml}$ liquid scintillation fluid (CytoScint; ICN Biomedicals) and counted with a Beckman LS 8100 . The epicardial disc samples were placed directly in scintillation fluid and counted. The levels of tritiated XAC in these samples were expressed as $\mathrm{dpm} \cdot \mathrm{ml}^{-1}$ after correcting for quench and counter efficiency. The levels of tritiated $\mathrm{XAC}$ in the epicardial and venous effuent samples were then expressed as a fraction of the levels in the arterial perfusate.

Statistical analysis

All values shown are mean(SEM). Statistical comparisons between individual means were made with analysis of variance followed by the Fisher LSD test. A probability of $\mathrm{p}<0.05$ indicated a significant difference between values.

\section{Results}

The first series of experiments was designed to evaluate the effects of 200 or $400 \mathrm{nM}$ XAC on hypoxic vasodilatation. The effect of XAC on coronary vascular resistance (fig 1) was similar to its effect on coronary perfusion pressure 
(table 1). As shown in fig 1, hypoxia reduced coronary vascular resistance in the absence or presence of XAC $(p<0.05)$. XAC did not significantly alter normoxic coronary resistance $(p>0.05)$ but 200 and $400 \mathrm{nM}$ XAC increased hypoxic coronary resistance $(\mathrm{p}<0.05)$. In addition, hypoxic coronary resistance in the presence of $400 \mathrm{nM} \mathrm{XAC}$ was greater than in the presence of $200 \mathrm{nM} \mathrm{XAC}(\mathrm{p}<0.05)$. Hypoxia decreased coronary vascular resistance by 37 (SEM $4) \%$ in the absence of XAC and by $26(5) \%$ and $17(4) \%$ in the presence of 200 or $400 \mathrm{nM}$ XAC, respectively.

The effect of XAC vehicle ( 20 or $40 \mu \mathrm{N} \mathrm{NaOH}$ ) on hypoxic vasodilatation is also shown in table I. Hypoxia reduced coronary perfusion pressure in the absence or presence of 20 or $40 \mu \mathrm{N} \mathrm{NaOH}(\mathrm{p}<0.05)$ and neither concentration of $\mathrm{NaOH}$ significantly altered the vasodilatation.

The concentrations of XAC in the arterial perfusate, venous effluent, and epicardial fluid before and during perfusion of the heart with XAC were determined directly by radioreceptor assay $(n=5)$ or indirectly as tritiated XAC $(\mathrm{n}=2)$. During perfusion with 200 or $400 \mathrm{nM}$ XAC, concentrations of XAC were $182(66)$ and $429(121) \mathrm{nM}$ in the arterial perfusate, respectively, $186(55)$ and $430(108) \mathrm{nM}$ in the venous effluent, respectively, and $335(35)$ and $571(107) \mathrm{nM}$ in the epicardial fluid respectively. In two additional experiments, we perfused the heart with $200 \mathrm{nM}$ tritiated XAC and determined the levels of tritiated XAC in

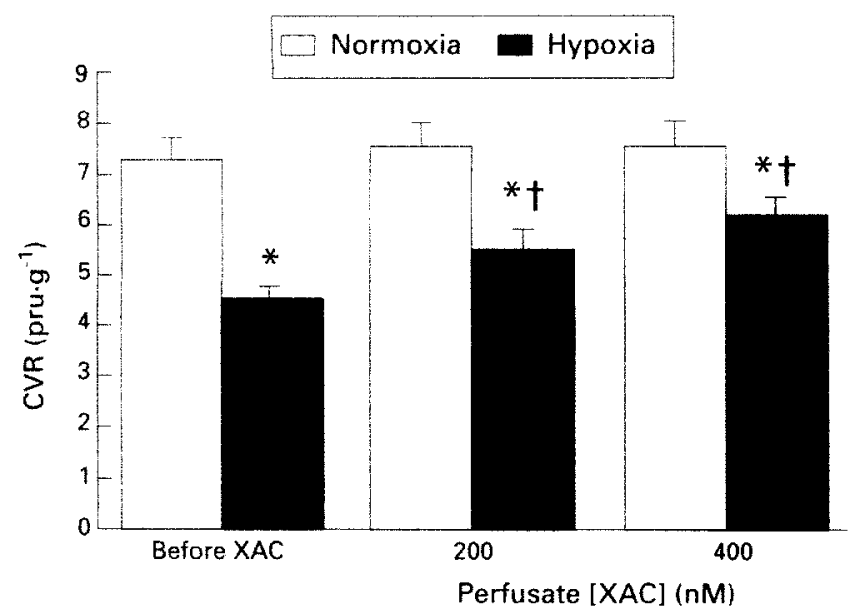

Figure 1 Coronary vascular resistance (CVR) during normoxia and hypoxia in the absence or presence of 200 or $400 \mathrm{nM} \mathrm{XAC.}$ * Significant difference from the CVR during preceding normoxia $(p<0.05)$; significant difference from $C V R$ during preceding hypoxia $(p<0.05) ; n=7$.

Table I Coronary perfusion pressure (CPP) and flow during normoxia and hypoxia in the absence or presence of $X A C$ or vehicle (NaOH). Values are means(SEM).

\begin{tabular}{lll}
\hline & \multicolumn{2}{c}{ Coronary perfusion pressure $(\mathrm{mm} \mathrm{Hg})$} \\
\cline { 2 - 3 } & Normoxia & Hypoxia \\
\hline Before XAC & $65(2)$ & $40(2)^{*}$ \\
$200 \mathrm{nM} \mathrm{XAC}$ & $66(2)$ & $48(3)^{*+}$ \\
$400 \mathrm{nM}$ XAC & $67(3)$ & $55(3)^{*+\frac{7}{+}}$ \\
Coronary flow $=9.0(0.3) \mathrm{ml} \cdot \mathrm{min}^{-1} \cdot \mathrm{g}^{-1}$ & \\
Before vehicle & $69(2)$ & $50(6)^{*}$ \\
$20 \mu \mathrm{N} \mathrm{NaOH}$ & $67(3)$ & $50(7)^{*}$ \\
$40 \mu \mathrm{HaOH}$ & $70(4)$ & $51(8)^{*}$ \\
Coronary flow $=9.9(0.3) \mathrm{ml} \cdot \mathrm{min}^{-1} \cdot \mathrm{g}^{-1}$ & \\
\hline
\end{tabular}

*Significant differences from CPP during preceding normoxia under the same concentrations of XAC or vehicle $(\mathrm{p}<0.05)$; t tsignificant differences from CPP during preceding hypoxia $(\mathrm{p}<0.05)$. each of these fluid compartments. The levels of tritiated $\mathrm{XAC}$ in the epicardial fluid was $77-100 \%$ of that in the arterial perfusate or venous effluent.

Figure 2 shows venous and epicardial adenosine concentrations during normoxia and hypoxia in the absence or presence of XAC. Hypoxia significantly increased venous adenosine concentration in the absence or presence of 200 or $400 \mathrm{nM}$ XAC. However, the mild degee of hypoxia used in this study did not produce a statistically significant increase in epicardial fluid adenosine concentration. Four hundred nanomolar XAC significantly increased the hypoxic venous and normoxic and hypoxic epicardial concentrations of adenosine.

Since the increase in venous adenosine concentration shown during hypoxia might be caused by the associated decrease in coronary perfusion pressure, we determined whether or not decreases in perfusion pressure alone increase venous adenosine concentration. Hearts were perfused with 0.1-3 $\mu \mathrm{M}$ pinacidil which decreased coronary perfusion pressure by $2-50 \%$ (fig 3 ). Pinacidil decreased perfusion pressure to a level which is similar to that produced by hypoxia. However, in contrast to the effect of hypoxia, pinacidil did not alter venous adenosine concentration.

The effect of XAC on intracoronary adenosine induced vasodilatation (series 3 experiments) is shown in table II and fig 4. Adenosine decreased coronary perfusion pressure and vascular resistance in the absence of XAC and these vasodilatations were attenuated by $100 \mathrm{nM} \mathrm{XAC}$ and blocked by $200 \mathrm{nM}$ XAC.

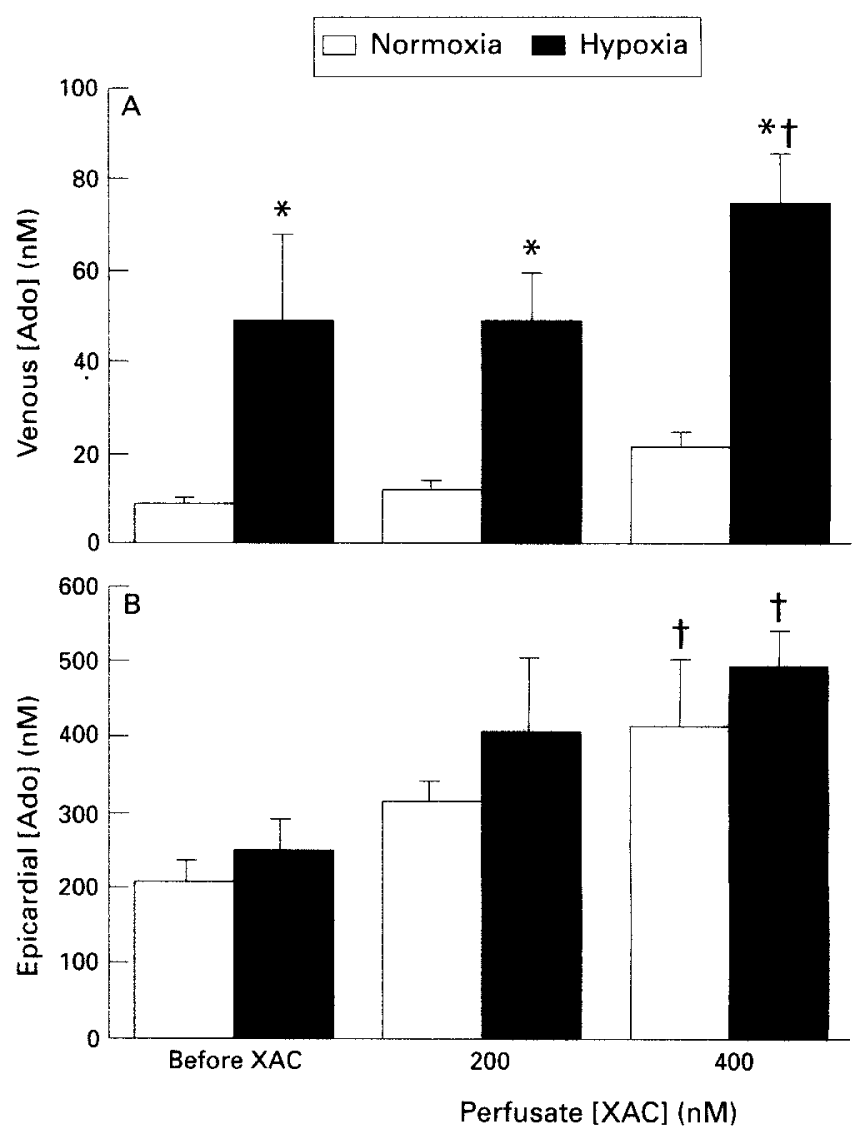

Figure 2 The levels of adenosine in coronary venous effluent $(A)$ and epicardial transudate $(B)$ during normoxia and hypoxia in the absence or presence of 200 or $400 \mathrm{nM} \mathrm{XAC}$.

* Significant differences from adenosine levels during the preceding normoxia $(p<0.05)$; †significant differences from the corresponding adenosine levels in the absence of XAC $(p<0.05): n=7$. 


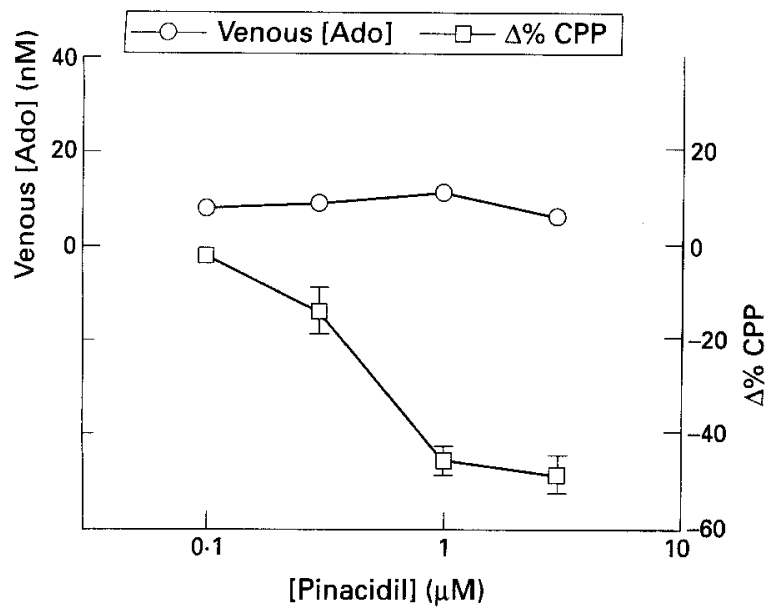

Figure 3 Venous adenosine concentration and percent decrease in coronary perfusion pressure (\% $\triangle \mathrm{CPP}$ ) induced by 0.1-3 $\mu \mathrm{M}$ pinacidil. All concentrations of pinacidil induced a significant decrease in CPP $(p<0.05)$ but did not alter the venous adenosine concentration. Coronary perfusion pressure and venous adenosine concentration before infusion of pinacidil were 64(SEM 2) $\mathrm{mm} \mathrm{Hg}$ and $11(3) n M$, respectively. Standard errors of the venous adenosine concentrations ([Ado]) are within the area of the symbols; $n=4$.

Table II Coronary perfusion pressure (CPP) and flow before and during intracoronary infusion of adenosine $\left(10^{-6} \mathrm{M}\right)$ in the absence or presence of XAC. Values are means $(S E M)$.

\begin{tabular}{lll}
\hline & \multicolumn{2}{c}{ Coronary perfusion pressure $(\mathrm{mm} \mathrm{Hg})$} \\
\cline { 2 - 3 } & Before adenosine & During adenosine \\
\hline Before XAC & $61(2)$ & $39(3)^{*}$ \\
$100 \mathrm{nM} \mathrm{XAC}$ & $63(3)$ & $56(4)^{* \dagger}$ \\
$200 \mathrm{nM} \mathrm{XAC}$ & $63(3)$ & $60(3) \dagger$ \\
Coronary flow $=10.3(0.4)$ & $\mathrm{ml} \cdot \mathrm{min}^{-1} \cdot \mathrm{g}^{-1}$ & \\
\hline
\end{tabular}

*Significant differences from CPP preceding the adenosine infusion $(\mathrm{p}<0.05)$; † significant difference from CPP during adenosine infusion in the absence of XAC $(\mathrm{p}<0.05)$.

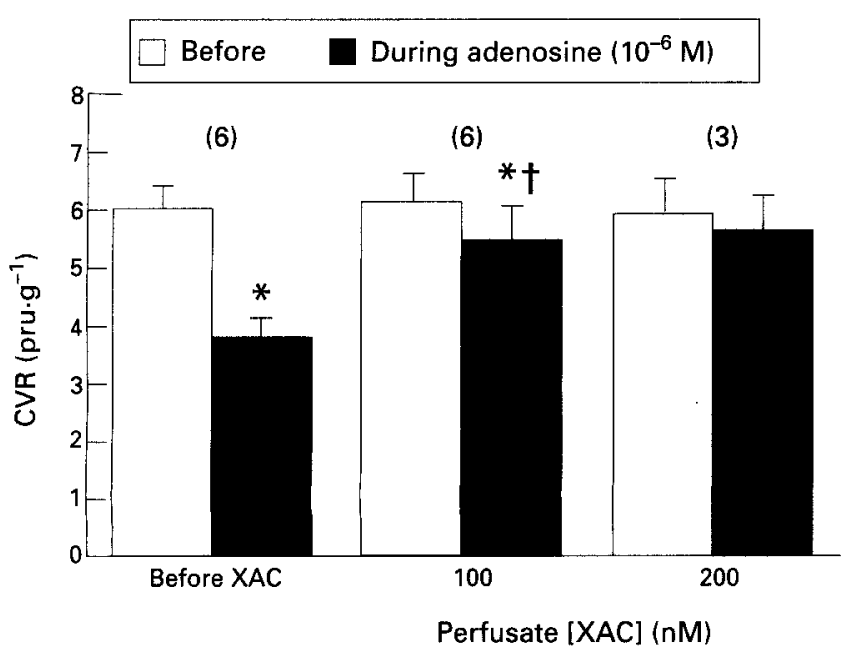

Figure 4 Coronary vascular resistance (CVR) before and during $10^{-6} \mathrm{M}$ intracoronary adenosine in the absence or presence of 100 or $200 \mathrm{nM} \mathrm{XAC}$

* Significant differences from the CVR preceding the adenosine infusion $(p<0.05)$; $\dagger$ significant difference from the $C V R$ during adenosine infusion in the absence of $X A C(p<0.05)$; numbers of experiments in parentheses.

\section{Discussion}

The present study used the potent adenosine receptor antagonist, XAC, to determine more clearly the role of adenosine in hypoxic myocardial vasodilatation. This is the first study to measure simultaneously vascular and interstitial levels of adenosine and a competitive adenosine receptor antagonist, as well as coronary resistance, during myocardial hypoxia. The results indicate that XAC rapidly equilibrates between the vascular and interstitial spaces of the isolated guinea pig heart. XAC increased hypoxic coronary resistance but did not alter the normoxic resistance, suggesting that adenosine plays a role in hypoxic but not normoxic vascular resistance. In addition, XAC attenuated $54 \%$ of hypoxic vasodilatation, confirming the results of other studies which show that adenosine deaminase ${ }^{5-9}$ or adenosine receptor antagonists ${ }^{6}{ }^{10}$ partially reverse hypoxic vasodilatation. The present results also show that XAC substantially increases epicardial and venous adenosine concentrations. Increases in myocardial adenosine concentration might overcome to some extent the adenosine receptor blockade by XAC, reducing the effectiveness of XAC in increasing hypoxic coronary resistance and attenuating the hypoxic vasodilatation. Therefore the effect of XAC on this vasodilatation probably underestimates the true extent of the involvement of adenosine in this vasodilator response.

Hypoxic vasodilatation is thought to be mediated in part by interstitial adenosine produced by myocardial cells and acting on adenosine receptors located on the abluminal surface of the vascular smooth muscle. ${ }^{1-3}$ If this is the case, then the ability of adenosine deaminase or receptor antagonists to attenuate the vasodilatation depends on the ability of these compounds to enter the interstitial fluid. It has recently been shown that intracoronary infusion of adenosine deaminase into the isolated guinea pig heart does not result in rapid equilibration of this enzyme between the vascular and interstitial spaces of the heart. ${ }^{12}$ This is predictable, based on the high molecular weight of this enzyme $(36 \mathrm{kDa})$. The weak adenosine receptor antagonist, theophylline, required 20 minutes to equilibrate between the vascular and interstitial spaces of the heart in anaesthetised dogs in vivo. ${ }^{11}$ In the present study performed with isolated guinea pig hearts, 6-12 minutes of intracoronary infusion of XAC caused the epicardial concentration of XAC to reach levels which in fact tended to be greater than in the arterial perfusate. The precise reason for this "concentrating" effect is not presently known. For example, it is not known if XAC, a weak base, is trapped within the interstitial fluid by binding to structures such as adenosine receptors or sialic acid residues on the surface of cell membranes. While our results may be at odds with those showing slow equilibration of theophylline, ${ }^{11}$ the discrepancy may be explained in part by the fact that saline perfusion markedly increases vascular permeability. ${ }^{24}$ The present study shows that in the Langendorff perfused guinea pig heart, the inability of XAC to cause total blockade of hypoxic vasodilatation is not due to the inability of this compound to reach the interstitial fluid and equilibrate within it.

Our results confirm other studies which show that adenosine receptor blockade increases myocardial adenosine concentrations. ${ }^{13}{ }^{14}$ In the present study (fig 2), $400 \mathrm{nM} \mathrm{XAC}$ increased venous and epicardial adenosine concentrations by about 25 and $200-250 \mathrm{nM}$, respectively. It is unlikely that these increases alone overcame by a significant extent the adenosine receptor blockade by $400 \mathrm{nM}$ XAC. As shown in fig 4, 100-200 nM XAC were sufficient to attenuate greatly 
or block the vasodilatation produced by $1 \mu \mathrm{M}$ adenosine. However, XAC might also increase midmyocardial and endocardial adenosine concentrations. Endocardial adenosine concentration in the normoxic resting guinea pig heart starts at 3-5 $\mu \mathrm{M} .^{25}$ If XAC doubles this interstitial concentration, as it did the epicardial concentration (fig 2), then the increase might be sufficient to overcome at least partially the receptor blockade by XAC. The precise reason for the XAC induced increases in adenosine concentration is not known. It has been hypothesised that adenosine acts as a mediator in the feedback system which couples myocardial oxygen requirements to coronary flow (oxygen supply). ${ }^{126}$ During adenosine receptor blockade, the feedback loop is opened and adenosine production may necessarily increase further to maintain total coronary flow and distribution.

It is notable that hypoxia alone did not increase the epicardial adenosine concentration (fig 2). This is surprising since hypoxia is known to be a potent stimulus for increasing myocardial adenosine concentration. ${ }^{1-6}$ In addition, the guinea pig hearts used in this study were perfused by constant flow, which should favour the interstitial accumulation of adenosine and other vasoactive metabolites during hypoxia. It is possible that hypoxic vasodilatation is not necessarily associated with global increases in interstitial adenosine concentration, particularly during mild hypoxia. Mild hypoxia might induce significant increases in endocardial and midmyocardial adenosine concentration without altering the epicardial concentration. In addition, the epicardial disc technique used in this study may not be sufficiently precise to detect the small increase in interstitial adenosine produced by this mild degree of hypoxia. Unfortunately, the effects of hypoxia on endocardial and midmyocardial adenosine levels were not determined in the present study but remain an important area for future investigation.

In contrast to the lack of effect of mild hypoxia on epicardial adenosine concentration, fig 2 shows that this level of hypoxia produced significant increases in venous adenosine concentration. It is therefore possible that blood vessels themselves are a significant source of adenosine ${ }^{35} 36$ and that this adenosine acts locally on the coronary vasculature to mediate hypoxic vasodilatation. The increase in venous adenosine concentration shown in the present study was indeed caused by hypoxia and not by the hypoxia induced decrease in coronary perfusion pressure alone. As shown in fig 3, similar decreases in perfusion pressure induced by pinacidil did not increase venous adenosine concentration.

Another interesting finding is that $100-200 \mathrm{nM} \mathrm{XAC}$ greatly attenuated or blocked the vasodilatation induced by $1 \mu \mathrm{M}$ intracoronary adenosine (fig 4), but $200 \mathrm{nM}$ XAC did not produce maximum attenuation of the hypoxic vasodilatation (fig 1). Indeed, $400 \mathrm{nM}$ XAC produced more attenuation of the hypoxic vasodilatation than did $200 \mathrm{nM}$ $\mathrm{XAC}$. Recent evidence indicates that within the range of adenosine concentrations which cause coronary vasodilatation, the action of intracoronary adenosine is primarily limited to the endothelium. ${ }^{1821}$ Perfusion of isolated guinea pig hearts with $0.01-1 \mu \mathrm{M}{ }^{14} \mathrm{C}$ or ${ }^{3} \mathrm{H}$ adenosine causes preferential labelling of the endothelium as assessed by autoradiography or by measurement of the radioactivity in endothelial cells detached from the hearts with collagenase/ trypsin. ${ }^{18}$ In addition, perfusion with 6 or $12 \mu \mathrm{M}$ adenosine causes maximal vasodilatation ${ }^{2}{ }^{19}$ but did not raise the adenosine levels in the interstitial fluid. ${ }^{21}$ Therefore, the present results appear to indicate that $100-200 \mathrm{nM} \mathrm{XAC}$ is sufficient to attenuate greatly or block the vasodilatation induced by activation of vascular endothelial adenosine receptors with 1 $\mu \mathrm{M}$ adenosine. The fact that the effect of XAC disassociate adenosine induced and hypoxia induced vasodilatation appears to suggest that endothelial adenosine receptors are not primarily responsible for hypoxic vasodilatation. It is likely that hypoxic vasodilatation is mediated by adenosine receptors located on vascular smooth muscle as originally proposed. ${ }^{1-3}$ It is notable also that endothelial and vascular smooth muscle cells seem to possess different adenosine receptor subtypes with different affinities for adenosine. ${ }^{27}$

Recent studies show that factors in addition to adenosine may also play a role in hypoxic coronary vasodilatation. These factors include prostaglandins, ${ }^{6829}$ ATP, ${ }^{30}$ ATP sensitive $\mathrm{K}^{+}$channels, ${ }^{31}{ }^{32}$ and endothelium derived nitric oxide. ${ }^{6}{ }^{30}$ 32-34 Further studies will be needed to determine how these compounds interact with each other and with adenosine to mediate hypoxic vasodilatation.

In conclusion, the results from the present study indicate that: (1) adenosine mediates at least $54 \%$ of hypoxic vasodilatation in the isolated constant flow perfused guinea pig heart; (2) hypoxic vasodilatation may not necessarily be associated with global increases in interstitial adenosine concentration, particularly during mild hypoxia; (3) blockade of adenosine receptors by XAC increases the interstitial concentration of endogenous adenosine, which may partially overcome the blockade; (4) XAC more effectively attenuates the vasodilatation induced by intracoronary adenosine than that caused by hypoxia. The reason for this preferential effectiveness of XAC is unclear, but it appears to underscore the minimal role played by vascular endothelial adenosine receptors in hypoxic coronary vasodilatation.

The authors are grateful for the excellent technical assistance of James Miller. They also appreciate the generosity of Dr Richard Green at the University of Illinois for providing the tritiated XAC. The research was supported by NIH research grants Nos HL 10384 and HL 37942.

Key terms: vasodilatation; interstitial fluid; epicardial discs; adenosine receptors.

Received 19 July 1993; accepted 29 November 1993. Time for primary review 32 days.

1 Berne RM. Cardiac nucleotides in hypoxia: possible role in regulation of coronary blood flow. Am I Physiol 1963;204: 317-22.

2 Berne RM. The role of adenosine in the regulation of coronary blood flow. Circ Res 1980;47:807-13.

3 Olsson RA, Pearson JD. Cardiovascular purinoceptors. Physiol Rev 1990;70:761-845.

4 Headrick JP, Matherne GP, Berne RM. Myocardial adenosine formation during hypoxia: effects of ecto-5'-nucleotidase inhibition. J Mol Cell Cardiol 1992;24:295-303.

5 Headrick JP, Willis RJ. Adenosine formation and energy metabolism: a ${ }^{31}$ P-NMR study in isolated rat heart. Am J Physiol 1990;258:H617-24.

6 Park KH, Rubin LE, Gross SS, Levi R. Nitric oxide is a mediator of hypoxic coronary vasodilation. Relation to adenosine and cyclooxygenase-derived metabolites. Circ Res 1992;71: 992-1001.

7 Merrill GF, Downey HF, Jones CE. Adenosine deaminase attenuates canine coronary vasodilation during systemic hypoxia. Am J Physiol 1986;250:H579-83.

8 Merrill GF, Downey HF, Yonekura S, Watanabe N, Jones CE. Adenosine deaminase attenuates canine coronary vasodilation during regional non-ischaemic myocardial hypoxia. Cardiovasc Res 1986;22:345-50.

9 Wei HM, Kang YH, Merrill GF. Coronary vasodilation during global myocardial hypoxia: effects of adenosine deaminase. $A m$ Physiol 1988;254:H1004-9.

10 Lee SC, Mallet RT, Shizukuda Y, Williams AG, Downey HF. Canine coronary vasodepressor responses to hypoxia are 
attenuated but not abolished by 8-phenyltheophylline. $A m J$ Physiol 1992;262:H955-60.

11 Gidday JM, Esther JW, Ely SW, Rubio R, Berne RM. Timedependent effects of theophylline on myocardial reactive hyperaemias in the anaesthetized dog. Br J Pharmacol 1990; 100:95-101.

12 Zhu Q, Matherne GP, Curnish RR, Tribble CG, Berne RM. Effect of adenosine deaminase on cardiac interstitial adenosine. Am $J$ Physiol 1992;263:H1322-6.

13 Ely SW, Matherne GP, Coleman SD, Berne RM. Inhibition of adenosine metabolism increases myocardial interstitial adenosine concentrations and coronary flow. J Mol Cell Cardiol 1992; 24:1321-32.

14 McKenzie JE, Steffen RP, Haddy FJ. Effect of theophylline on adenosine production in the canine myocardium. Am J Physiol 1987;252:H204-10.

15 Linden J. Structure and function of $\mathrm{A} 1$ adenosine receptors. FASEB J 1991;5:2668-76.

16 Belardinelli L, Linden J, Berne RM. The cardiac effects of adenosine. Prog Cardiovasc Dis 1989;32:73-97.

17 Headrick JP, Berne RM. Endothelium-dependent and -independent relaxations to adenosine in guinea pig aorta. Am $J$ Physiol 1990;259:H62-7.

18 Nees S, Herzog V, Becker BF, Bock M, DesRosiers C, Gerlach E. The coronary endothelium: a highly active metabolic barrier for adenosine. Basic Res Cardiol 1985;80:515-29.

19 Matherne GP, Headrick JP, Berne RM. Ontogeny of adenosine response in guinea pig heart and aorta. Am J Physiol 1990; 259:H1637-42.

.20 Gidday JM, Kaiser DM, Rubio R, Berne RM. Heterogeneity and sampling volume dependence of epicardial adenosine concentrations. J Mol Cell Cardiol 1992;24:351-64.

21 Tietjan CS, Tribble CG, Gidday JM, et al. Interstitial adenosine in guinea pig hearts: an index obtained by epicardial disks. Am J Physiol 1990;259:H1471-6.

22 Linden J, Earl CQ, Patel A, Craig RH, Daluge SM. Agonist and antagonist radioligands and photoaffinity labels for the adenosine Al receptor. In: Gerlach E, Becker BF, eds. Topics and perspectives in adenosine research. Berlin: Springer Verlag, 1987: 3-14.

23 Jacobson KA, Ukena D, Kirk KL, Daly JW. $\left[{ }^{3} \mathrm{H}\right]$ Xanthine amine congener of 1,3-dipropyl-8-phenylxanthine: an antagonist radio- ligand for adenosine receptors. Proc Natl Acad Sci USA 1986; 83:4089-93.

24 Chambers RW, Zweifach BW. Intracellular cement and capillary permeability. Physiol Rev 1947;27:436-63.

25 Zhu Q, Headrick JP. Berne RM. Transmural distribution of extracellular purines in isolated guinea pig heart. Proc Natl Acad Sci USA 1991;88:657-60.

26 Bardenheuer H, Schrader J. Supply-to-demand ratio for oxygen determines formation of adenosine by the heart. Am J Physiol 1986;250:H173-80.

27 Tucker AL, Linden J. Cloned receptors and cardiovascular responses to adenosine. Cardiovasc Res 1993;27:62-7.

28 Baur TS, Brodowicz GR, Lamb DR. Indomethacin suppresses the coronary flow response to hypoxia in exercise trained and sedentary rats. Cardiovasc Res 1990;24:733-6.

29 Okada T. Hypoxia-induced change in prostanoids production and coronary flow in isolated rat heart. J Mol Cell Cardiol 1991: 23:939-48.

30 Hopwood AM, Lincoln J, Kirkpatrick KA, Burnstock G. Adenosine-5'-triphosphate, adenosine and endothelium-derived relaxing factor in hypoxic vasodilation of the heart. Eur $J$ Pharmacol 1989;165:323-6.

31 Daut J, Maier-Rudolph W, Von Beckerath N, Mehrke G, Gunther $\mathrm{K}$, Goedel-Meinen L. Hypoxic dilation of coronary arteries is mediated by ATP-sensitive potassium channels. Science 1990; 247:1341-4.

$32 \cdot$ Von Beckerath N, Cyrys S, Dischner A, Daut J. Hypoxic vasodilation in isolated, perfused guinea pig heart: an analysis of the underlying mechanisms. J Physiol (Lond) 1991;442: 297-319.

33 Brown IP, Thompson CI, Belloni FL. Role of nitric oxide in hypoxic coronary vasodilation in isolated perfused guinea pig heart. Am J Physiol 1993;264:H821-9.

34 Busse R, Trigisch G, Bassenge E. The role of endothelium in the control of vascular tone. Basic Res Cardiol 1985;80:475-90.

35 Bardenheuer H, Whelton B, Sparks HV. Adenosine release by the isolated guinea pig heart in response to isoproterenol, acetylcholine and acidosis: the minimal role of vascular endothelium. Circ Res 1987;61:594-600.

36 Deussen A, Moser G, Schrader J. Contribution of coronary endothelial cells to cardiac adenosine production. Pflugers Arch 1986;406:608-14.

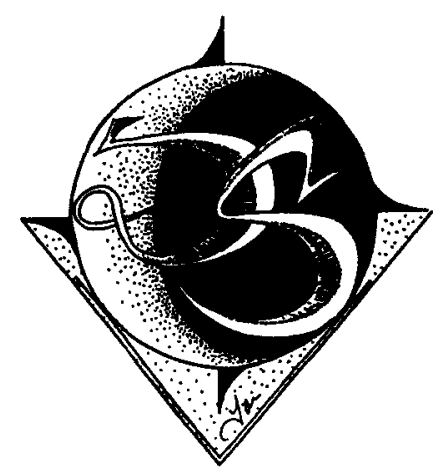

